Authors post print version / Additive Manufacturing journal (Elsevier)

Volume 33, May 2020, 101129

https://doi.org/10.1016/i.addma.2020.101129

\title{
Increasing the productivity of Laser Powder Bed Fusion: influence of the hull-bulk strategy on part quality, microstructure and mechanical performance of Ti-6Al-4V
}

Charlotte de Formanoir ${ }^{1}$, Umberto Paggi1, 2, Thomas Colebrants ${ }^{1,2}$, Lore Thijs², Guichuan Li $^{3}$, Kim Vanmeensel $^{3}$, Brecht Van Hooreweder ${ }^{1}$

1 KU Leuven, Department of Mechanical Engineering, Celestijnenlaan 300, 3001 Leuven, Belgium

2 3D Systems Leuven, Grauwmeer 14, 3001 Leuven, Belgium

${ }^{3}$ KU Leuven, Department of Materials Engineering, Kasteelpark Arenberg 44, 3001 Leuven, Belgium

\begin{abstract}
To increase the productivity of Laser Powder Bed Fusion (LPBF), a hull-bulk strategy can be implemented. This approach consists in using a high layer thickness in the core of the part, hence reducing the build time, and a low layer thickness in the skin, to maintain a high accuracy and good surface finish. The present study investigated to what extent this strategy affected the surface roughness, relative density, microstructure and mechanical properties of Ti-6Al-4V parts. Ti-6Al-4V specimens were built using two distinct sets of process parameters, one optimized for a $90 \mu \mathrm{m}$-layer thickness in the bulk and the other for a $30 \mu \mathrm{m}$-layer thickness in the hull. In addition to surface roughness and relative density measurements, a thorough microstructure analysis was done using both optical microscopy and SEM. Additionally, EBSD measurements and numerical reconstruction of the parent $\beta$ grains were performed to evaluate the mesostructure and texture evolution from hull to bulk. Microhardness measurements and tensile tests were done to assess the effect of the hull-bulk strategy on the mechanical properties. This analysis was completed on both as-built and stress-relieved specimens. The present study demonstrated the possibility of using the hull-bulk strategy to build high-quality Ti-6Al-4V parts, without impacting their tensile properties, hence increasing the productivity of the process by a geometrydependent factor, typically ranging between $25 \%$ and $100 \%$.
\end{abstract}

\section{Keywords}

Ti-6Al-4V, LPBF, productivity, graded microstructure, tensile properties

\section{Introduction}

Laser Powder Bed Fusion (LPBF), also known as Selective Laser Melting (SLM) or direct metal printing (DMP), offers many advantages, in particular a higher design freedom than conventional manufacturing. The layer-by-layer approach inherent to additive manufacturing (AM) allows the building of complex geometries and custom-made designs. In comparison with other AM processes for metals, such as Electron Beam Melting (EBM) or Directed Energy Deposition (DED), LPBF offers a high accuracy. This is related to the fine layer thickness and relatively small powder size distribution typically used in the LPBF process. However, the ability of LPBF to manufacture parts with a high resolution is counterbalanced by the low productivity of the process. The build rate of LPBF is indeed typically lower than that of other powder-bed AM processes, such as EBM. To illustrate this, Table 1 provides a comparison of the productivity of an LPBF ProX320 machine and an EBM Arcam A1 machine, considering a build job of 256 tensile bars, i.e. the capacity limit of an Arcam A1 EBM machine. 


\begin{tabular}{|c|c|c|}
\hline \multirow{3}{*}{ LPBF (ProX320) } & $\begin{array}{c}\text { Layer thickness } \\
(\mu \mathrm{m})\end{array}$ & $\begin{array}{c}\text { Build time } \\
\text { (hours) }\end{array}$ \\
\cline { 2 - 3 } & 30 & 111 \\
\cline { 2 - 3 } & 60 & 89 \\
\cline { 2 - 3 } & 90 & 28 \\
\hline EBM (Arcam A1) & 120 & 25 \\
\cline { 2 - 3 } & 50 & 36 \\
\hline
\end{tabular}

Table 1 - Build time required to build 256 ASTM E8M size 6 Ti-6Al-4V tensile bars using the ProX320 LPBF machine or the Arcam A1 EBM machine, considering different layer thicknesses (results are based on a study performed internally at 3D Systems).

The build rate is directly proportional to the layer thickness, scanning velocity and hatch spacing. Increasing the layer thickness is therefore a straightforward approach to improve the productivity [1] but directly impacts the surface roughness and geometrical accuracy of the part [2] and requires a thorough process parameters optimization in order to avoid the formation of lack-of-fusion porosity [3]. The trade-off between part quality and productivity remains one of the major obstacles to a wider industrialization of the LPBF process. To address this issue, various approaches have been developed and implemented, such as increasing the machine's build volume to reduce operating time, or using multiple laser beam sources and multiple laserscanning systems in one machine ("twin-laser" or "quad-laser" [4]) so that the build area can either be multiplied or that one build space can be processed by several lasers and scanningsystems at the same time [5]. However, these approaches involve significant research and development and typically lead to more expensive LPBF machines.

In order to combine geometrical accuracy and process productivity, while avoiding the use of larger or more expensive machines, a "hull-bulk" strategy (also known as "hull-core" or "skincore" strategy) can be implemented [4][6]. This approach consists of applying a high precision parameter set for the hull (or skin) of the part, and a high productivity parameter set for its bulk (or core). From a practical point of view, this can be achieved by varying the spot size and laser power. As mentioned by Poprawe et al. [5], a large beam setting with high laser power combined with a large hatch spacing can be used for the bulk, whereas a fine beam is used to build the outer shape of the parts (skin). This approach was proposed by Schleifenbaum et al. [6], who used a duo-laser set-up and by Metelkova et al. [7], who increased the spot size by defocusing the laser beam. Scanning with varying spot sizes, however, was out of scope for this study, as it requires significant hardware modifications.

A simpler method, which can be applied as such in state-of-the-art industrial LPBF machines, without hardware adaptation, consists in using two different sets of process parameters in the bulk and in the hull. The hull is built with a conventional layer thickness, whereas a larger layer thickness and higher power are used for the bulk. This requires a preliminary process parameter optimization step, in order to define the optimal set of power, scanning speed and hatch spacing for this layer thickness.

Although the hull-bulk strategy is not new to the AM community [6][7][8], its impact on the material properties remains poorly understood for Ti-6Al-4V, one of the most widely used alloys in the AM industry. Koutny et al. [8] recently investigated the effect of this strategy on Al parts processed with a skin-core strategy, reporting the presence of a graded microstructure, but to the best of the authors knowledge, no such study was performed on Ti-6Al-4V.

In Ti-6Al-4V manufactured by LPBF, the meso- and microstructure are known to be closely related to the processing conditions [9][10]. The mesostructure of AM Ti-6Al-4V parts typically consists of columnar parent $\beta$ grains resulting from rapid solidification and epitaxial growth 
along the thermal gradient [11][12][13]. In addition, the high cooling rate of the LPBF process determines the final microstructure within the prior $\beta$ grains, which is martensitic in as-built condition [11][14]. Given the close correlation between process parameters and microstructure, the use of different processing conditions in the bulk and in the hull might result in the genesis of distinctive microstructures, hence impacting the mechanical properties. In order to validate the use of the hull-bulk strategy in critical industrial applications, it is essential to determine to what extent this strategy impacts the microstructure and mechanical properties of LPBF Ti-6Al-4V parts. Hence, the present study investigated the meso- and microstructure in the skin, core and skin-core interface and evaluated how the presence of a gradient in mesostructure impacted the quasi-static mechanical properties of the material. In addition to a thorough microstructural characterization, microhardness and uniaxial tensile properties were evaluated in order to establish structure-property relationships. The effect of a subsequent stress-relief posttreatment was also investigated.

\section{Methods}

\subsection{Hull-bulk strategy}

The hull-bulk strategy was realized by employing the Supermiddle build style of the XHP LaserForm Ti Gr23 material available in the 3DXpertTM software: the skin was printed with the optimized standard parameters for a $30 \mu \mathrm{m}$ layer thickness (LT), while the core was printed with the Extra High Productivity Upgrade parameters ( $90 \mu \mathrm{m}$ layer thickness), as illustrated in Figure 1. For each layer thickness, the corresponding energy density $E_{v}=\frac{P}{v h t}$ is reported in Table 2. An extensive DOE was performed in order to define the best combination of hull thickness and width of the overlap between hull and bulk.

All specimens were printed on a 3DSystems ProX ${ }^{\circledR}$ DMP 320 machine, using LaserForm ${ }^{\circledR}$ Ti Gr23 (A) powder.

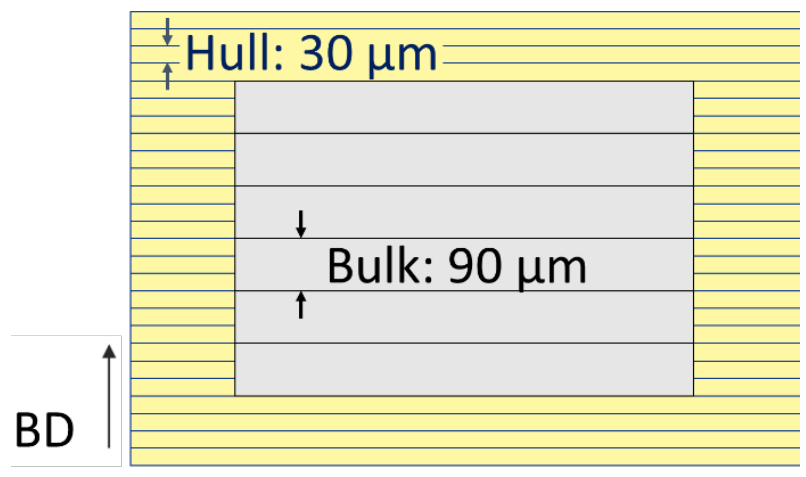

Figure 1 - Schematic representation of the hull-bulk strategy (drawing is not to scale)

\begin{tabular}{|c|c|c|}
\hline & $\begin{array}{c}\text { layer thickness t } \\
{[\mu \mathrm{m}]}\end{array}$ & $\begin{array}{c}\text { energy density } \\
{\left[\mathrm{J} / \mathrm{mm}^{3}\right]}\end{array}$ \\
\hline hull & 30 & 58.9 \\
\hline bulk & 90 & 30.2 \\
\hline
\end{tabular}

$\underline{\text { Table } 2}$ - Layer thickness and corresponding volumetric energy density used for the hull and for the bulk.

In the implementation of the hull-bulk strategy, while the contours and hull were scanned for every new layer of powder that was deposited, the bulk was only printed every three layers, as illustrated in Figure 2. In the overlap region between hull and bulk, three consecutive layers of 
material were first successively melted using the $30 \mu \mathrm{m}$ LT process parameters and then remelted once with the $90 \mu \mathrm{m}$ LT parameter set. Scheifenbaum et al. [6] highlighted the importance of an overlap to assure a dense metallurgical bonding between the hull and the bulk. The absence of an overlap would have resulted in a poor hull-to-bulk cohesion, due to the separate volume shrinkage taking place during solidification of the core and of the skin due to consecutive scanning of these two areas.

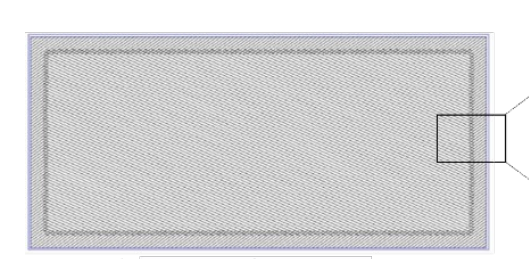

layer $n$, layer $n+3$

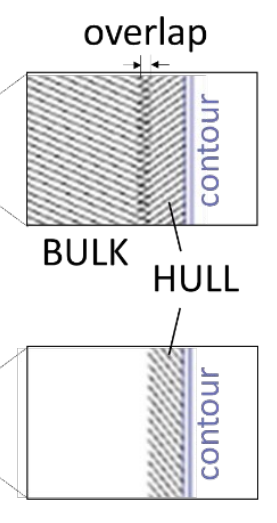

layer $\mathrm{n}+1$, layer $\mathrm{n}+2$

Figure 2 - Scanning vectors in each layer of a hull-bulk part: the hull was scanned every layer, whereas the bulk was scanned every three layers.

\subsection{Sample geometry}

To evaluate the effect of the hull-bulk strategy on density, microstructure and surface quality, specimens with various geometrical features, including an inclined and a semi-spherical surfaces, were manufactured. This geometry is shown in Figure 3.a. The following sample references were used:

- "R30" for the reference parameter set for a $30 \mu \mathrm{m}$ layer thickness,

- "R90" for the reference parameter set for a $90 \mu \mathrm{m}$ layer thickness,

- "HB30+90" for the combination of both parameter sets, i.e. hull-bulk specimens.
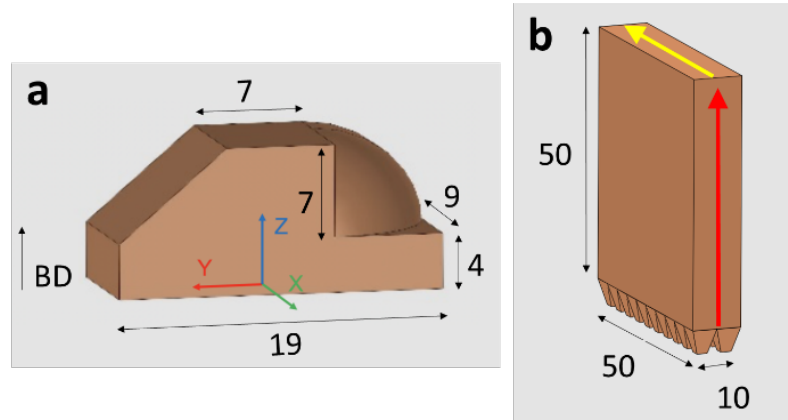

Figure 3 - Geometry of the samples used for microstructure and microhardness analyses (a) and for roughness measurements (b). The dimensions are reported (in $\mathrm{mm}$ ). The red and yellow arrows show the stylus path along the build direction and top surface, respectively.

Additionally, in order to evaluate the anisotropy in tensile properties, tensile specimens were built in three different orientations: horizontally $\left(0^{\circ}\right)$, vertically $\left(90^{\circ}\right)$ and diagonally $\left(60^{\circ}\right)$, as illustrated in Figure 4. The geometry of the tensile specimens was designed according to the ASTM E8M standard for round specimens. For each of the three directions, 10 R30 specimens and 
10 HB30+90 were built. Stress relief (SR) was then performed on half of the specimens (i.e. 5 specimens of each condition). The stress-relief post-treatment was performed at $670^{\circ} \mathrm{C}$, for $5 \mathrm{~h}$.

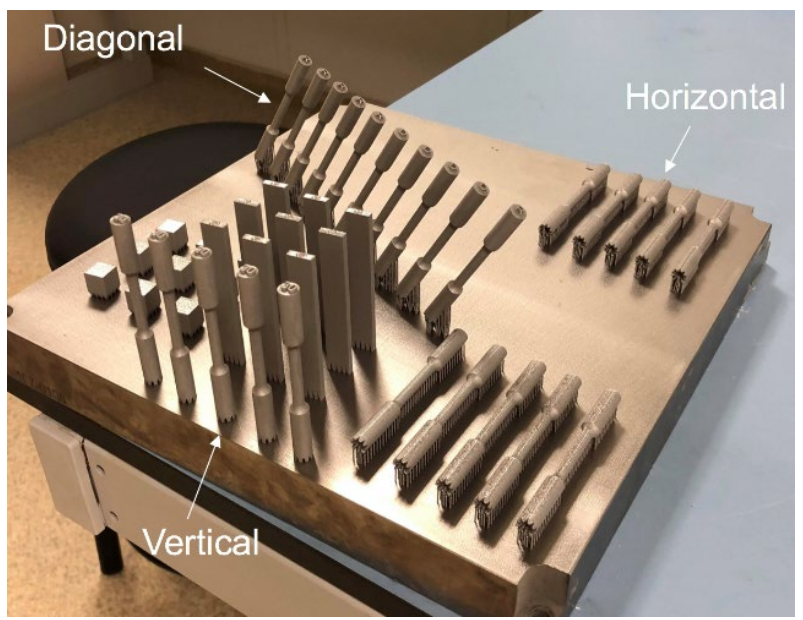

Figure 4 - Positioning and orientation of the tensile specimens on the build plate

\subsection{Density, surface roughness and microstructure analysis}

The relative density was evaluated with the "pixel count" approach. Micrographs of cross-sections in the ZY plane were obtained using a Nikon MA100 microscope, with a $5 \mathrm{x}$ lens magnification. Image analysis was then performed using the ImageJ software. For each specimen, the optical density was averaged from five micrographs.

A Taylor Hobson Form Talysurf-120L instrument was used for surface roughness measurements of the R30, R90 and HB30+90 specimens. A rectangular prism was printed (Figure 3.b) and roughness evaluation was performed on the smaller sides. The acquisition length and filtering of the raw profile were performed according to ISO 4288-1996. For each surface, 5 adjacent profiles were measured and averaged.

A Keyence VHX6000 microscope was used to perform optical microscopy. Higher magnification micrographs were obtained using a Philips XL30 FEG SEM, using secondary electron contrast with an acceleration voltage of $10 \mathrm{kV}$. In addition, EBSD scans of a $250 \mu \mathrm{m} \times 600 \mu \mathrm{m}$ area were performed along the build direction in both the hull and the core, using an accelerating voltage of $20 \mathrm{kV}$, and a step size of $0.5 \mu \mathrm{m}$. In order to perform texture analysis on a larger scale, an EBSD scan of $1 \mathrm{~mm} \times 1 \mathrm{~mm}$ with a step size of $1 \mu \mathrm{m}$ was done on the cross-section of a hull-bulk specimen, perpendicularly to the build direction. Prior to EBSD, the samples underwent a mechanical polishing followed by a $2 \mathrm{~h} 30$ chemical-mechanical polishing step using a $70 \%$ colloidal silica suspension and $30 \% \mathrm{H}_{2} \mathrm{O}_{2}(30 \%)$ solution. Based on the existence of the Burgers orientation relationship between the body-centered cubic $\beta$ phase and the hexagonal $\alpha^{\prime}$ phase, a numerical reconstruction of the parent $\beta$ grains, from the room temperature $\alpha^{\prime}$ phase EBSD data, was performed, using a Matlab ${ }^{\circledR}$ code developed by Dr Loïc Malet (4MAT department, Université Libre de Bruxelles). The principle of the reconstruction is as follows. For each $\alpha^{\prime}$ pixel, the 6 possible parent $\beta$ orientations are computed. If neighbouring $\alpha^{\prime}$ pixels share a common parent orientation (within a given tolerance), this orientation is chosen as the orientation of the parent $\beta$ grain. In the EBSD map, the $\alpha^{\prime}$ pixels are replaced by the parent $\beta$ orientation. A similar procedure is followed by Germain et al. [15]. 


\subsection{Mechanical properties evaluation}

A CSM microhardness tester was used to perform Vickers indentation, with a $9.81 \mathrm{~N}$ load applied for a duration of $10 \mathrm{~s}$ for each indentation. Ten microhardness measurements were done in the hull, at a distance of $1 \mathrm{~mm}$ from the surface, and ten were done in the bulk, $10 \mathrm{~mm}$ away from the surface. In addition, 20 measurements were done from the hull to the bulk. The distance between each indent was $500 \mu \mathrm{m}$.

Tensile tests were done according to ASTM-E8M, in both as-built (AB) and stress-relieved (SR) conditions. For each condition (AB - SR) and direction (horizontal, vertical, diagonal), 5 tensile specimens were tested. All specimens were tested in as-built surface condition, meaning that no post-process machining or surface treatment was performed. The tensile tests were done on a Shimadzu AG-XD plus tensile bench, at a strain rate of $1 \mathrm{~mm} / \mathrm{min}$, until fracture. A Shimadzu TRViewX digital video extensometer was used for strain measurement. After tensile testing, fracture surface analysis was performed using a Philips XL30 FEG SEM, using secondary electron contrast with an acceleration voltage of $10 \mathrm{kV}$.

\subsection{Productivity calculation}

The use of a hull-bulk strategy directly impacts the laser scanning time $t_{l s}$. The laser scanning time required when using the $30 \mu \mathrm{m}$ layer thickness parameter set was calculated and compared to the scanning time needed when applying the hull-bulk strategy. This theoretical comparison was performed for three different geometries and various dimensions: a fully dense cube, a complex demonstration part, and a lattice structure (Figure 5). A relatively high scaffold density of $50 \%$ was chosen for the lattice structure, resulting in a strut diameter large enough to implement the hull-bulk strategy (i.e. larger than $2 \mathrm{~mm}$ ).

The total production time $t_{\text {prod }}$ was obtained by adding the laser scanning time, the coating time and the cooling time. From this value, the productivity $P$ was calculated:

$$
P=\frac{\text { volume }}{t_{\text {prod }}} \quad\left[\mathrm{mm}^{3} / \mathrm{s}\right]
$$

The productivity increase associated with the use of a hull-bulk strategy is equal to:

$$
\left(\frac{P_{H B}}{P_{L T 30}}-1\right) \times 100=\left(\frac{t_{\text {prod } L T 30}}{t_{\text {prod } H B}}-1\right) \times 100
$$
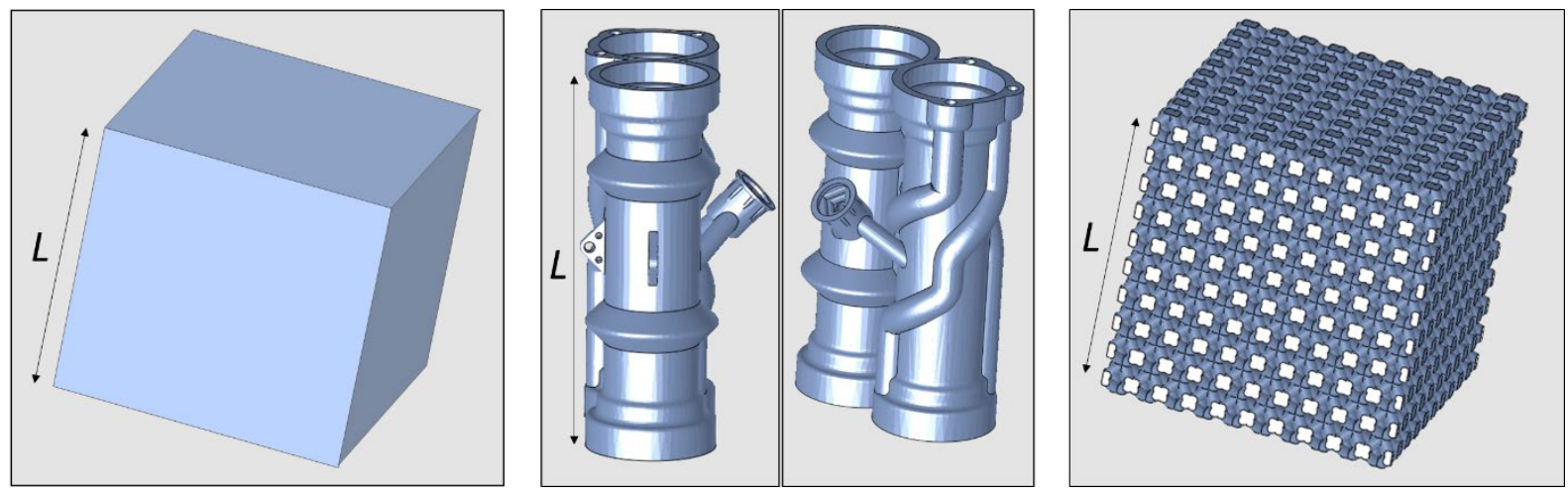

Figure 5 - Geometries chosen to evaluate the effect of the hull-bulk strategy on productivity. For each geometry, the productivity increase was calculated for four different values of $L$ : $L=1 \mathrm{~cm}, L=5 \mathrm{~cm}, L=10 \mathrm{~cm}, L=20 \mathrm{~cm}$ 


\section{Results}

\subsection{Density measurements}

The density measurements are reported in Table 3 with a confidence interval of 95\%. Similar density results were obtained for the two reference parts R30 and R90 and for the hull-bulk specimens HB30+90.

\begin{tabular}{|c|c|}
\hline & $\begin{array}{c}\text { Optical density } \\
{[\%]}\end{array}$ \\
\hline R30 & $99.91 \pm 0.05$ \\
\hline R90 & $99.88 \pm 0.07$ \\
\hline HB30+90 & $99.90 \pm 0.04$ \\
\hline
\end{tabular}

Table 3 - Density measurements obtained by optical microscopy (95\% confidence interval)

\section{2. $\underline{\text { Surface finish }}$}

The vertical side surfaces and horizontal top surfaces of reference R30 and R90 and hull-bulk HB30+90 specimens are reported in Figure 6. From a qualitative point of view, the hull-bulk part exhibited a side surface finish that is very similar to that of the reference specimen built with a $30 \mu \mathrm{m}$ layer thickness.

On the top surface of the HB30+90 specimens, a slight difference between the core area scanned with the $90 \mu \mathrm{m}$ layer thickness parameters and the area scanned built with the $30 \mu \mathrm{m}$ layer thickness parameter set was observed. In other words, the hull exhibited a slightly different top surface than the bulk.

The sample built with a $90 \mu \mathrm{m}$ layer thickness, on the other hand, exhibited a visibly higher surface roughness. In particular, as can be seen in Figure 6.h., the staircase effect on the inclined hemispherical top surface was much more visible than in the reference part built with a $30 \mu \mathrm{m}$ layer thickness (Figure 6.g.). This can be directly related to the larger melt pool dimensions, visible in Figure 6.b.

Surface roughness measurements, performed by tactile profilometry, are reported in Table 4. For both side and top surfaces, the $\mathrm{R}_{\mathrm{a}}$ values measured on the R30 part and those obtained on the hull-bulk specimen were very similar. In comparison, a much higher surface roughness was observed for the R90 part. These quantitative results confirmed the qualitative observations deduced from Figure 6, and demonstrated the ability of the hull-bulk strategy to produce parts with a surface quality comparable to that of parts entirely built with a fine layer thickness.

\begin{tabular}{|c|c|c|}
\hline & $\begin{array}{c}\text { Ra side surface } \\
{[\mu \mathrm{m}]}\end{array}$ & $\begin{array}{c}\text { Ra top surface } \\
{[\mu \mathrm{m}]}\end{array}$ \\
\hline R30 & $6.22 \pm 0.4$ & $4.32 \pm 0.4$ \\
\hline R90 & $10.13 \pm 0.7$ & $15.24 \pm 1.6$ \\
\hline HB30+90 & $6.95 \pm 0.2$ & $4.16 \pm 0.5$ \\
\hline
\end{tabular}

Table 4 -Surface roughness of the samples manufactured with the reference process parameters for $30 \mu \mathrm{m}$ and $90 \mu \mathrm{m}$ LT and comparison with the surface roughness of a hull-bulk specimen (95\% confidence interval) 

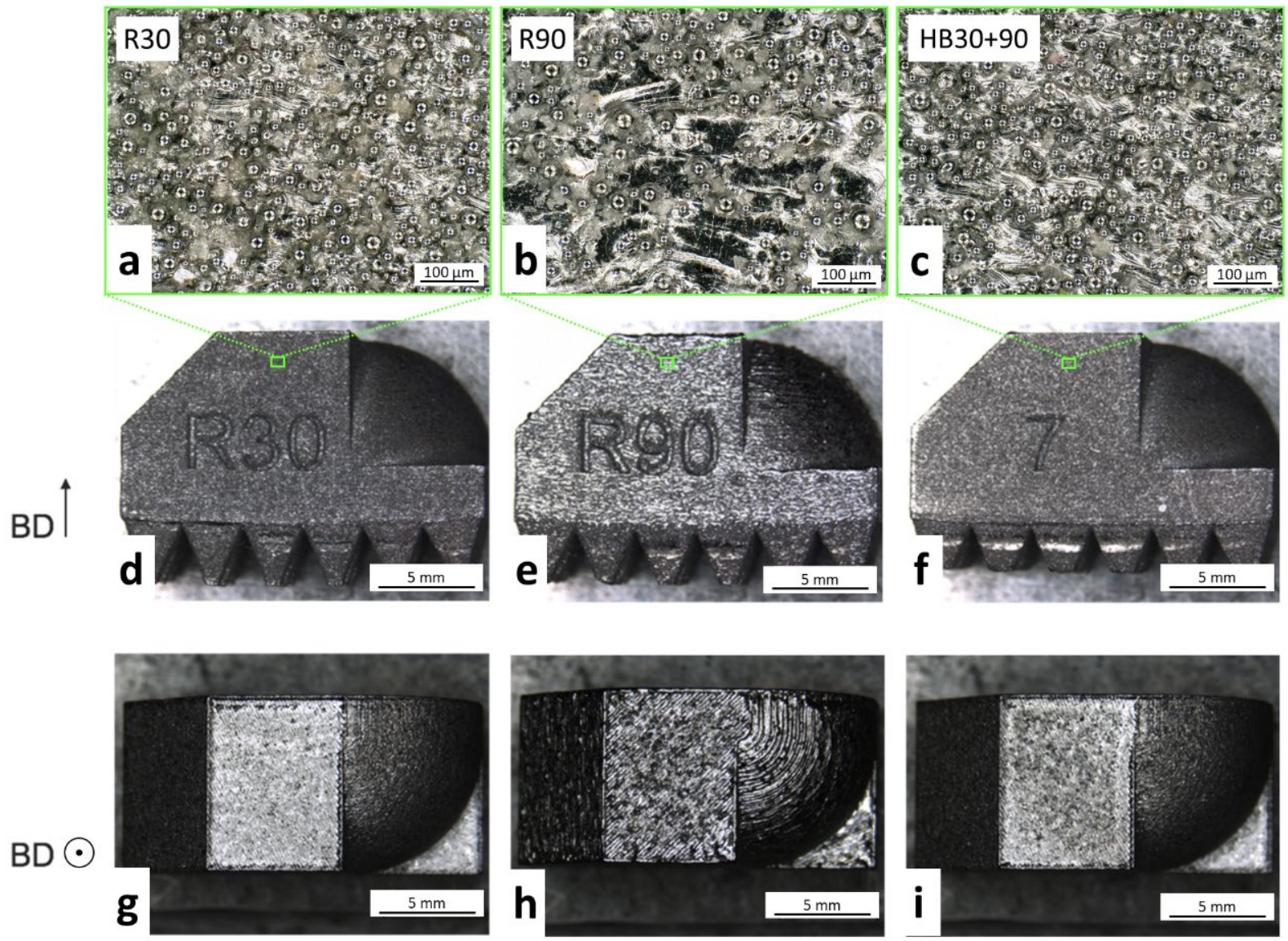

Figure 6 - Optical micrographs of the side surface and top surface of the reference parts $(a, d, g) R 30$ and ( $b$, $e, h) R 90$ and of $(c, f, i)$ the HB30+90 hull-bulk specimen.

\subsection{Microstructure}

Optical and SEM micrographs of a hull-bulk specimen are given in Figures 7 and 8. Figure 7 provides an overview of the hull, bulk, and hull-to-bulk transition. A graded mesostructure, with more elongated parent $\beta$ grains in the hull than in the bulk is observed in Figure 7 and in the higher magnification optical micrographs in Figure 8. This is also clearly visible in the IPF color maps of the hull (Figure 9.a.) and bulk (Figure 9.b.), and corresponding numerical reconstruction of the parent $\beta$ grains. The prior $\beta$ grains in the hull appeared to have a similar width to those in the bulk, i.e. about $90 \mu \mathrm{m}$, but exhibited a more columnar morphology, with an average length of $155 \mu \mathrm{m} \pm 111 \mu \mathrm{m}$ (std dev.) along the build direction. In the bulk, the average length of the $\beta$ grains was $66 \mu \mathrm{m} \pm 33 \mu \mathrm{m}$ (std dev.).

Figure 8 also depicts higher magnification micrographs of the microstructure within the prior $\beta$ grains, obtained by SEM-SE microscopy. In both the hull and the bulk, a very fine acicular microstructure, typical of $\alpha^{\prime}$ martensite was present. 


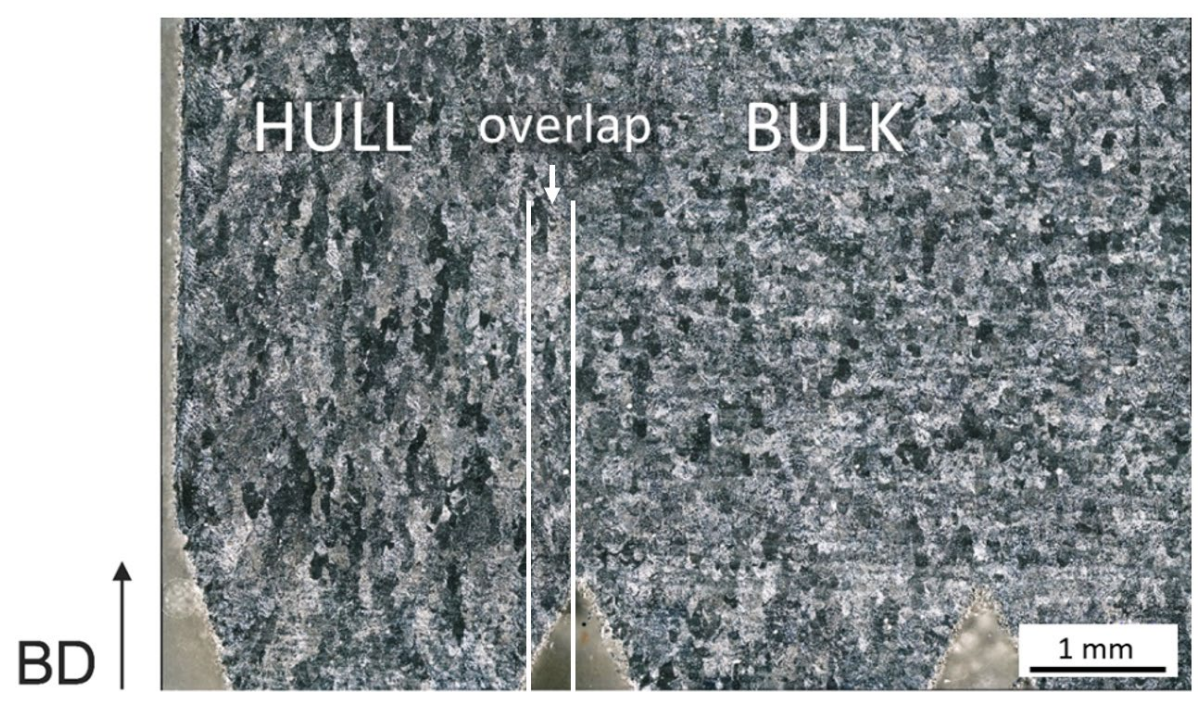

Figure 7 - Optical micrograph of a horizontal cross-section of a hull-bulk specimen. The arrow indicates the build direction (BD)
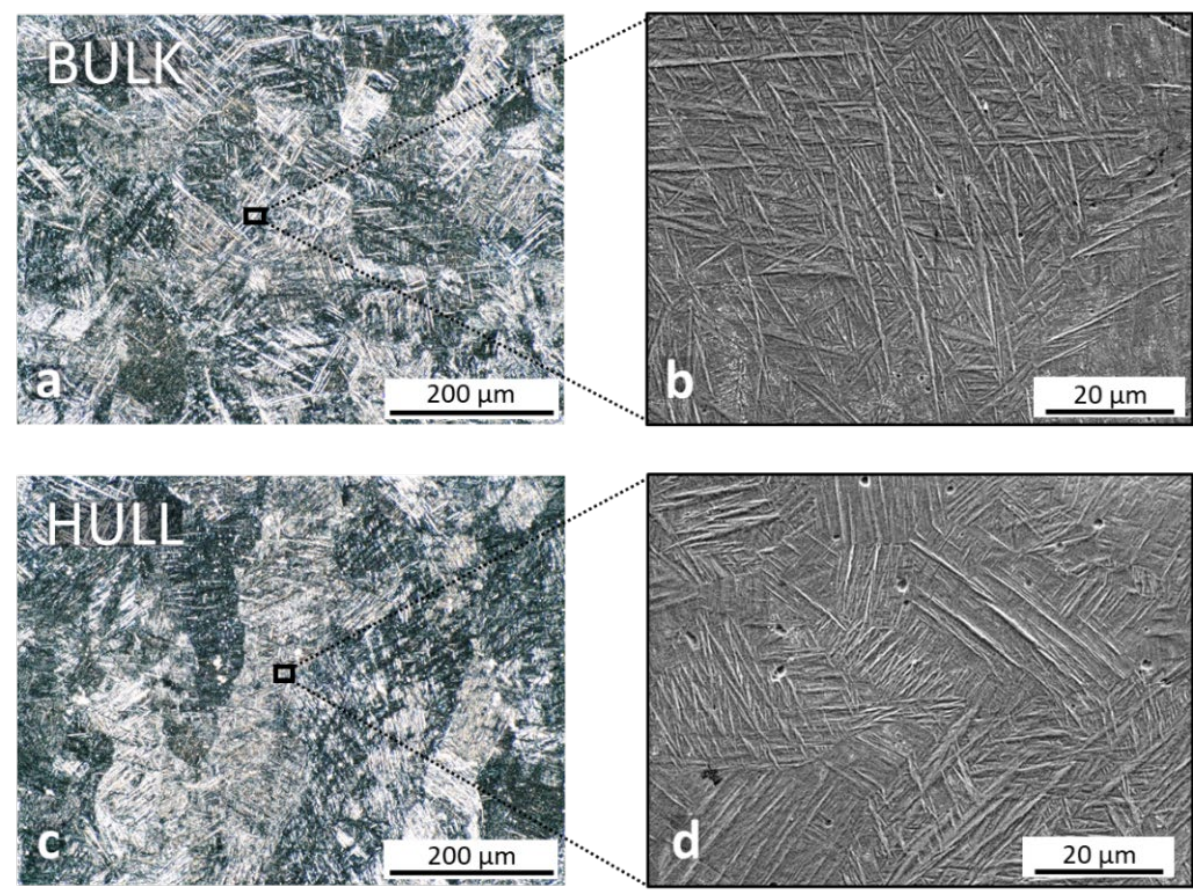

Figure 8-Optical and SEM (SE mode) micrographs of the $(a, b)$ bulk and $(c, d)$ hull.

In order to perform texture analysis, a larger EBSD scan was acquired on the xy-cross section of a HB30+90 tensile specimen. The resulting IPF color map and corresponding parent $\beta$ phase reconstruction are presented in Figure 10.a. and 10.b., respectively. This scan was mostly covering the bulk region, except for the upper left corner which was located in the hull. From the $<001>_{\beta}$ pole figure shown in Figure 10.d., it can be seen that the prior $\beta$ phase was not strongly textured, with a maximum texture intensity of 6.6 times random. The texture of the $\alpha$ phase was even weaker, as its intensity did not exceed 4.3 times random. The parent $\beta$ phase texture which is usually reported in additively manufactured Ti- $6 \mathrm{Al}-4 \mathrm{~V}$, i.e. with the $\langle 001\rangle_{\beta}$ direction parallel to the build direction [16][17][18], was not observed here. 

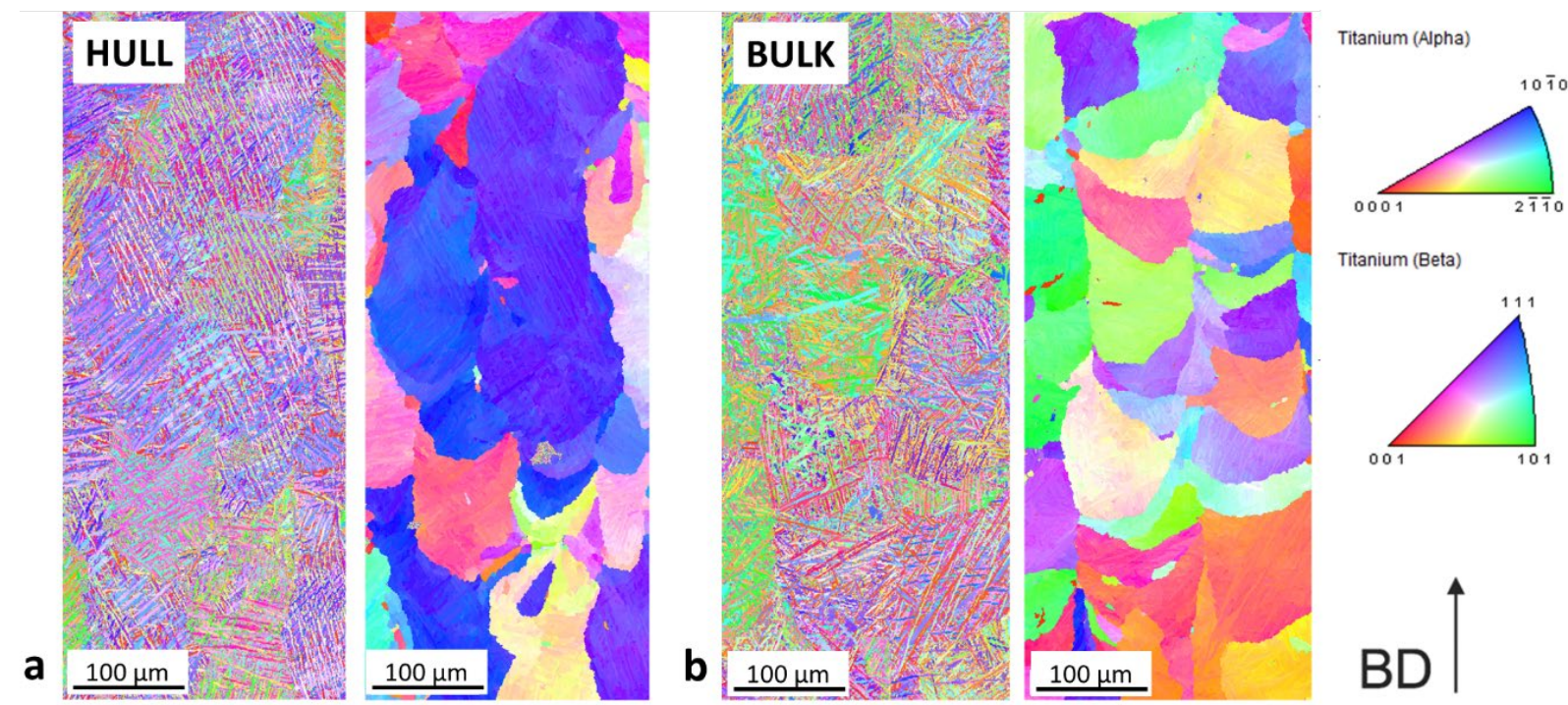

Titanium (Beta)

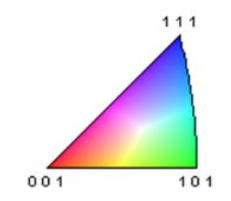

Figure 9 - IPF color maps of hull (a) and bulk (b) regions in a HB30+90 specimen, and corresponding numerical reconstruction of the parent $\beta$ grains.
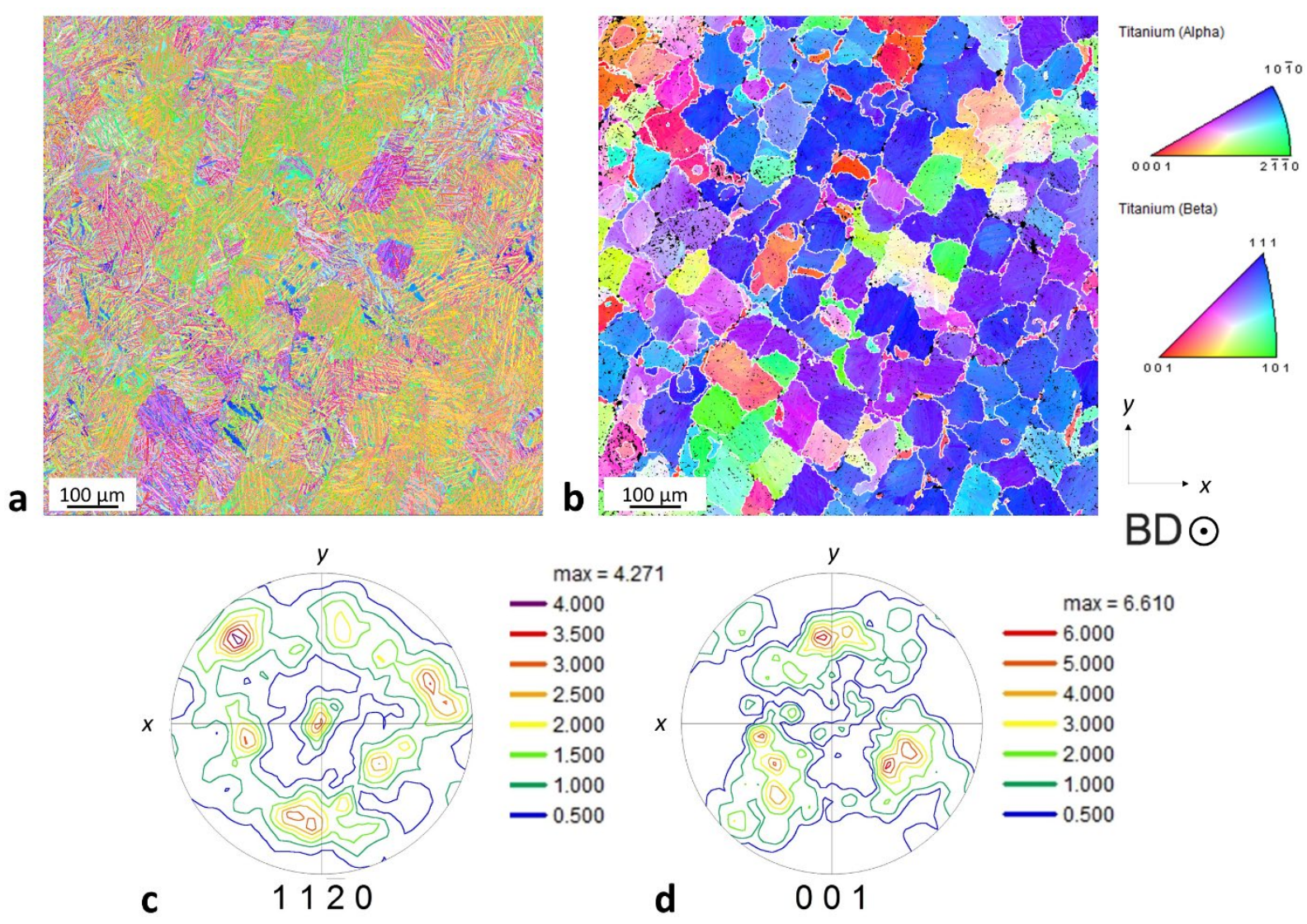

Titanium (Beta)

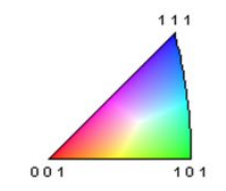

C

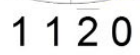

d

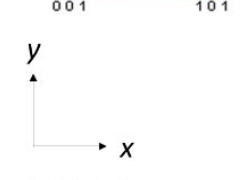

\section{$\mathrm{BD} \odot$}

Figure $10-($ a) IPF color map of a $1 \mathrm{~mm} \times 1 \mathrm{~mm} x y$-cross section of a HB30+90 tensile specimen and corresponding (b) numerical reconstruction of the parent $\beta$ grains, $(c)<11-20>_{\alpha}$ and $(d)<001>_{\beta}$ pole figures. 


\subsection{Microhardness}

Vickers microhardness measurements were performed in three different regions of the sample, as illustrated in Figure 11.a: along the build direction (BD) in the hull and in the bulk (Figure 11.b) and along the $\mathrm{x}$ direction from hull to bulk (Figure 11.c). No gradient in microhardness was observed between hull and bulk, and similar values were obtained in the hull (397 HV \pm 11 std dev.) and in the bulk (394 HV \pm 10 std dev.).

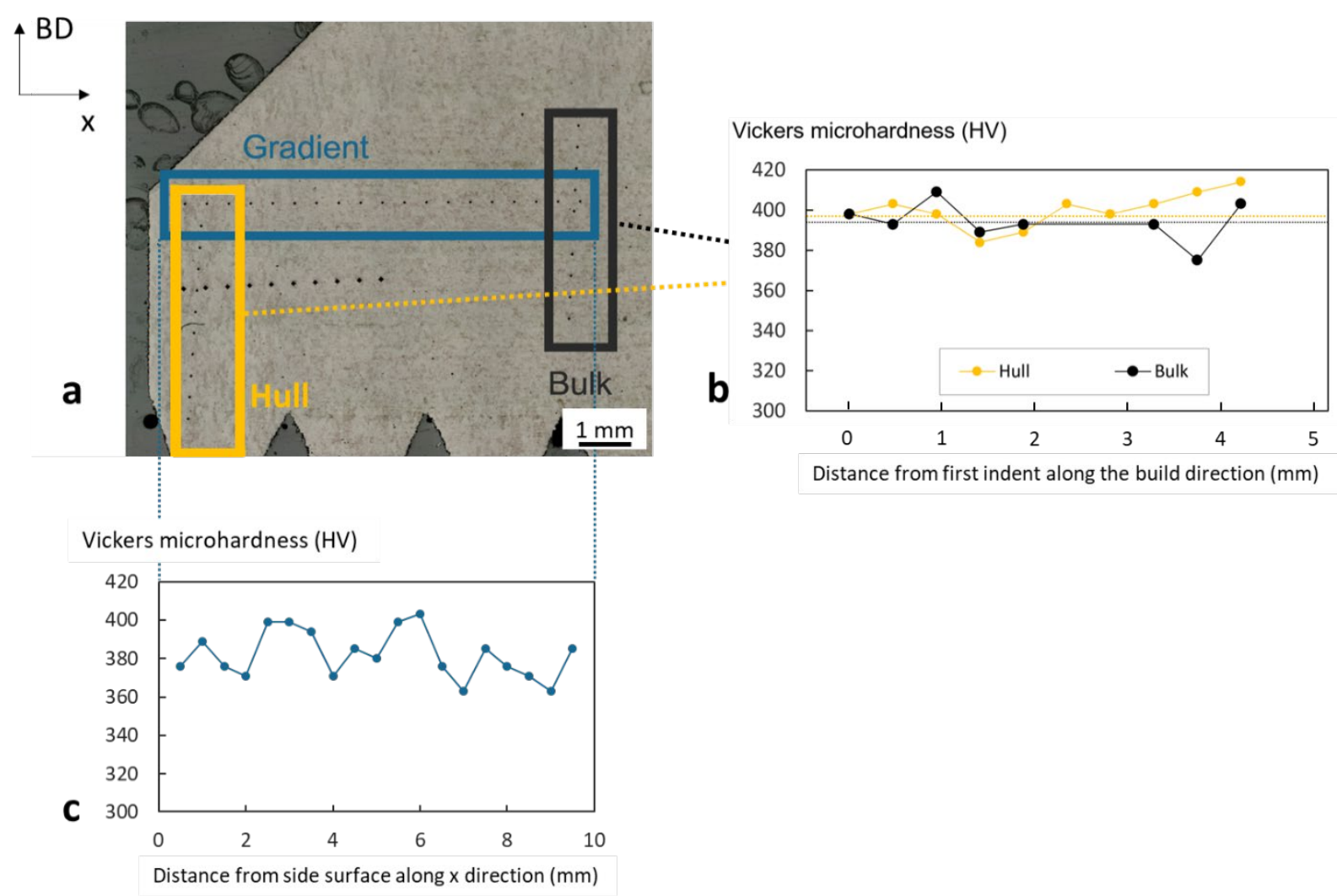

Figure 11 - Vickers microhardness measurements: (a) location of the indents in the sample and corresponding microhardness values (b) along the build direction in the hull and in the bulk and (c) along the $x$ direction from hull to bulk.

\subsection{Tensile properties}

Tensile specimens were built in three different directions (Figure 4), using either the hull-bulk strategy or the R30 reference strategy, and tested in both as-built and stress-relieved (SR) conditions. The results of the corresponding tensile tests are reported in Figure 12 and in Table 5. As can be observed in Figure 12, in both as-built and stress-relieved condition, for a given build orientation, specimens built with the hull-bulk strategy exhibited very similar tensile curves to those of reference specimens built with a $30 \mu \mathrm{m}$ layer thickness.

In as-built condition, when comparing the tensile behavior of specimens built along different orientations, the properties appeared to be very similar, although the vertical specimens had a slightly higher strength than the horizontal and diagonal specimens. Stress-relieved specimens displayed a lower strength than their as-built counterparts, with a decrease in ultimate tensile strength of about 200MPa. This reduction in strength was associated with an increase in ductility of more than $5 \%$ for diagonal and vertical specimens. It can however be noticed that horizontal stress-relieved specimens had a relatively poor strain at failure of about $10 \%$. It should be noticed that the horizontal specimens were tested in as-built surface condition and that full support 
removal was not possible. Likely, the surface roughness condition led to a premature failure of the parts.
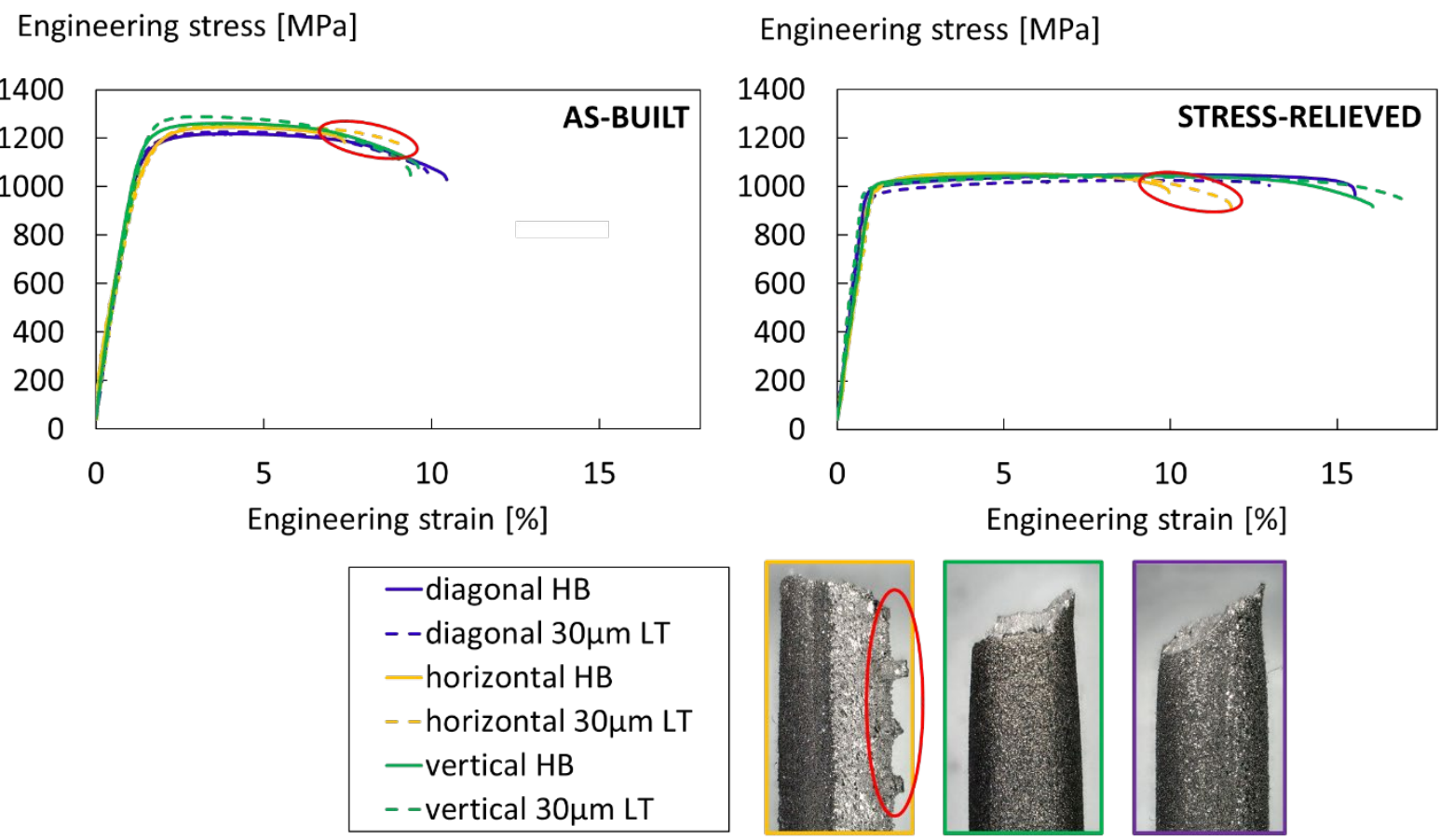

Figure 12 - Stress-strain curves of hull-bulk (HB) specimens and 30 $\mu$ m layer thickness (LT) specimens built along three different directions $\left(0^{\circ}, 60^{\circ}, 90^{\circ}\right)$, in as-built or stress-relieved condition. The low strain at failure observed in the horizontal specimens can be related to the presence of supports on the downfacing area.

\begin{tabular}{|c|c|c|c|c|}
\hline & $\begin{array}{c}\text { Young's } \\
\text { modulus E } \\
{[\mathrm{GPa}]} \\
\end{array}$ & $\begin{array}{c}\text { Yield strength } \\
\sigma_{\mathbf{y}, \mathbf{0 . 2} \%} \\
{[\mathrm{MPa}]} \\
\end{array}$ & $\begin{array}{c}\text { Max. stress } \\
\boldsymbol{\sigma}_{\mathbf{m}} \\
{[\mathrm{MPa}]} \\
\end{array}$ & $\begin{array}{c}\text { Elongation at } \\
\text { break } \\
{[\%]} \\
\end{array}$ \\
\hline horizontal $30 \mu \mathrm{m} \mathrm{LT}$ & $70 \pm 14$ & $1082 \pm 55$ & $1257 \pm 2$ & $9.2 \pm 0.9$ \\
\hline vertical $30 \mu \mathrm{m} \mathrm{LT}$ & $90 \pm 12$ & $1146 \pm 33$ & $1289 \pm 1$ & $9.3 \pm 0.5$ \\
\hline diagonal $30 \mu \mathrm{m}$ LT & $91 \pm 7$ & $1084 \pm 45$ & $1229 \pm 4$ & $9.3 \pm 0.6$ \\
\hline horizontal HB & $77 \pm 9$ & $1027 \pm 11$ & $1251 \pm 4$ & $8.8 \pm 1.0$ \\
\hline vertical HB & $95 \pm 5$ & $1118 \pm 24$ & $1259 \pm 1$ & $9.6 \pm 0.5$ \\
\hline diagonal HB & $96 \pm 17$ & $1091 \pm 20$ & $1227 \pm 7$ & $9.6 \pm 0.7$ \\
\hline horizontal $30 \mu \mathrm{m}$ LT - SR & $89 \pm 26$ & $1008 \pm 41$ & $1058 \pm 5$ & $10.2 \pm 1.2$ \\
\hline vertical $30 \mu \mathrm{m}$ LT - SR & $112 \pm 7$ & $995 \pm 7$ & $1041 \pm 5$ & $15.6 \pm 1.7$ \\
\hline diagonal $30 \mu \mathrm{m}$ LT - SR & $105 \pm 9$ & $974 \pm 19$ & $1019 \pm 6$ & $14.2 \pm 1.0$ \\
\hline horizontal HB - SR & $89 \pm 16$ & $1012 \pm 15$ & $1061 \pm 9$ & $9.4 \pm 0.9$ \\
\hline vertical HB - SR & $101 \pm 12$ & $1012 \pm 5$ & $1050 \pm 5$ & $15.7 \pm 0.7$ \\
\hline diagonal HB - SR & $110 \pm 5$ & $982 \pm 5$ & $1042 \pm 6$ & $14.8 \pm 2.1$ \\
\hline
\end{tabular}

Table 5 - Tensile properties (95\% confidence interval) of hull-bulk (HB) specimens and 30 $\mu$ m layer thickness (LT) specimens built along three different directions $\left(0^{\circ}, 60^{\circ}, 90^{\circ}\right)$, in as-built or stress-relieved (SR) condition.

Fractography analysis was performed on horizontal, diagonal and vertical samples built with the hull-bulk strategy. Side and top views of the fracture surfaces are given in Figure 13.a, b and c, respectively. The presence of supports on the horizontal specimen is highlighted in Figure 13.a. In horizontal specimens, the fracture appeared to initiate from one of the supports. The low elongation at failure of the horizontal specimens can be related to this observation. Apart from this, no major difference could be seen in the features of the fracture surfaces for the various processing conditions and orientations considered in this study. This is exemplified by the 
comparison of Figure 13.d and Figure 13.e. The fracture surface of the vertical hull-bulk specimen was very similar to that of the horizontal $30 \mu \mathrm{m}$ LT specimen.

a

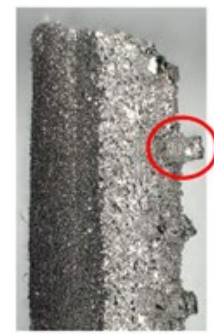

horizontal HB

b

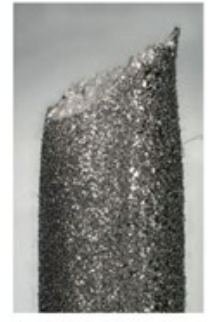

diagonal HB

C

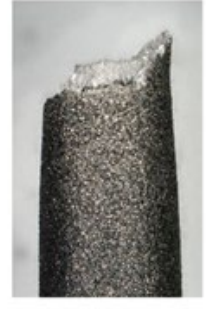

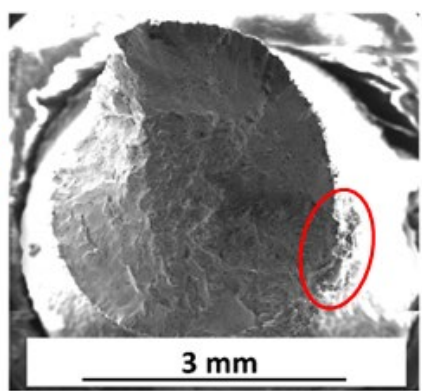
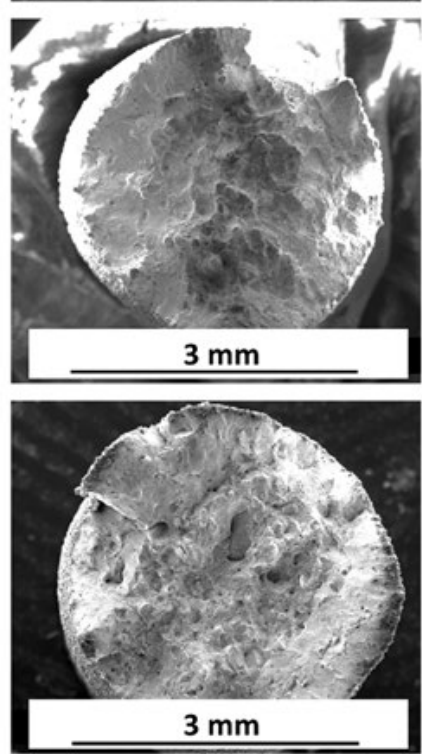

d

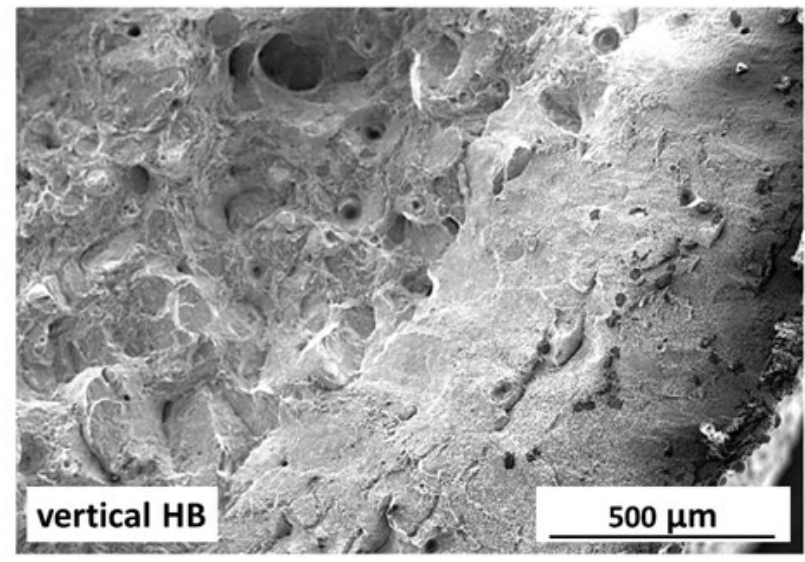

e

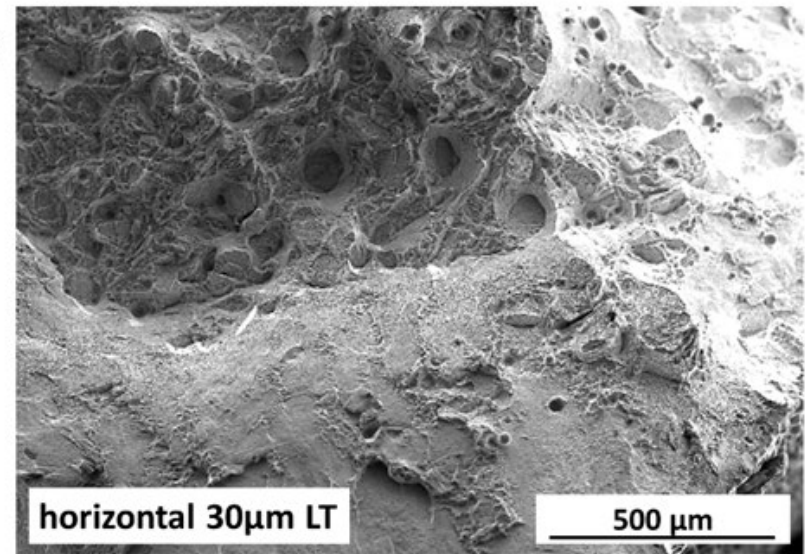

Figure 13 - OM side view and SEM-SE overall top view of the fracture surfaces of (a) horizontal, (b) diagonal and (c) vertical hull-bulk tensile specimens (as-built condition). Magnified SEM-SE view of the fracture surface of (d) a vertical hull-bulk specimen and of (e) a horizontal 30 $\mu$ m layer thickness specimen.

\subsection{Productivity increase}

The productivity increase associated with the use of a hull-bulk strategy was calculated for each of the three geometries illustrated in Figure 5. The results are reported in Figure 14. It can be seen that the effect of the hull-bulk strategy on productivity was highly dependent on the geometry and dimensions of the part. The highest productivity increase was obtained for the fully dense cube with an increase of up to $252 \%$ for a $20 \mathrm{~cm}$-side cube. In other words, the build time is in this case reduced by a factor of 3.52. Applying the hull-bulk strategy on the industrial use case resulted in a $116 \%$ productivity increase for a $20 \mathrm{~cm}$-long design. For the lattice design, however, the use of hull-bulk strategy led to a decrease in productivity, of about $5 \%$. 


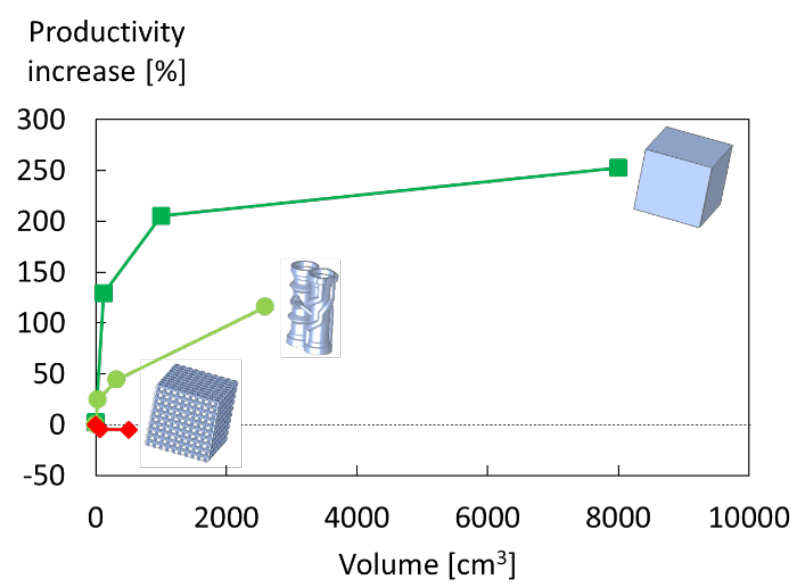

Figure 14 - Theoretical productivity increase calculated for various geometries and dimensions.

\section{Discussion}

\subsection{Part quality and productivity increase}

The hull-bulk strategy allows to build fully dense Ti-6Al-4V parts with a surface finish equivalent to that of reference parts, as demonstrated by the very similar relative densities and $R_{a}$ values obtained in hull-bulk parts compared to $30 \mu \mathrm{m}$ LT specimens. While equivalent part quality is achieved, the build time can be significantly reduced by applying the hull-bulk strategy. However, as previously mentioned, this productivity increase was highly dependent on the geometry and dimensions of the part. In Figure 15, the productivity increase calculated for the various abovementioned geometries and dimensions is reported as a function of the surface-to-volume ratio. It can be seen that in relatively large and bulky parts, with a low surface-to-volume ratio, the use of the hull-bulk strategy induced a very significant increase in productivity. It should however be highlighted that such bulky geometries are not representative of the typically more complex parts built by AM. With its very low surface-to-volume ratio, the cubic geometry gave an upper range of the maximum productivity improvement that could be achieved with a hull-bulk strategy. The industrial demonstration part was a more realistic AM application for which the implementation of a hull-bulk strategy resulted in a productivity increase ranging between $24 \%$ for a 5 -cm height to $116 \%$ for a 20 -cm height.

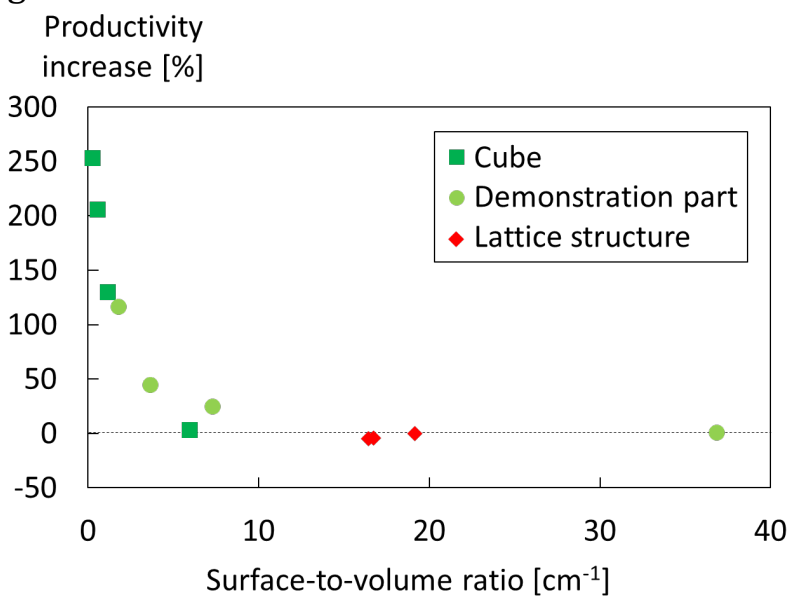

Figure 15 - Theoretical productivity increase as a function of surface-to-volume ratio

Lower productivity increase values were obtained for high surface-to-volume ratios. Above a threshold value of about $10 \mathrm{~cm}^{-1}$, the production time became comparable to, or even higher than, that required to build the same parts with a standard $30 \mu \mathrm{m}$ layer thickness. The decrease in productivity observed in the case of the lattice structure could be related to the very small area that was printed with a $90 \mu \mathrm{m}$ layer thickness and to the comparatively large overlap area which 
was scanned twice in the process (see Figures 1 and 2). Additionally, the hull-bulk strategy added complexity to the scan lines and increased the number of idle jumps of the laser. For this type of intricate designs, the use of a hull-bulk strategy is therefore not advised.

\subsection{Influence of the hull-bulk processing conditions on meso- and microstructure}

As illustrated in Figures 7 to 9, the mesostructure in the hull of the specimens differed from that observed in the bulk. On the one hand, the hull material built with a $30 \mu \mathrm{m}$ layer thickness exhibited a columnar mesostructure, with $\beta$ grains elongated along the build direction. This morphology, typical of LPBF Ti-6Al-4V, resulted from the epitaxial growth of the $\beta$ grains during solidification. It was favored by the high volumetric energy density used to process the hull, which led to deep heat penetration. On the other hand, the bulk - manufactured with the $90 \mu \mathrm{m} \mathrm{LT}$ parameter set - presented a different mesotructure. The shape of the $\beta$ grains was hemispherical or semi-elliptical, and appeared to be related to the morphology of the melt pools. This type of solidification microstructure has been reported for a variety of alloys processed by LPBF [19][2], but is rarely observed in Ti-6Al-4V processed by LPBF [9][20], which normally contains columnar prior $\beta$ grains parallel to the build direction, sometimes several millimeters long [13][16][21]. Despite very high solidification rates, and $10 \mathrm{wt} \%$ alloying elements, Ti-6Al-4V typically does not produce equiaxed grains during AM. This is due to the high partition coefficients of $\mathrm{Al}$ and $\mathrm{V}$, and consequently narrow solidification range, that limits constitutional supercooling and nucleation of equiaxed grains ahead of the solidification front [22]. The bulk was built here with a volumetric energy density $E_{v \text { bulk }}=30.2 \mathrm{~J} / \mathrm{mm}^{3}$, i.e. twice as low as the energy density applied in the hull, $E_{v \text { hull }}$ $=58.9 \mathrm{~J} / \mathrm{mm}^{3}$. This resulted in a reduced temperature gradient and a faster $\mathrm{S} / \mathrm{L}$ interface displacement velocity, promoting a sufficient constitutional undercooling by segregating solutes, which further improved the nucleation of equiaxed $\beta$ grains in the bulk. Consequently, the $\langle 001\rangle_{\beta}$ parallel to build direction texture that typically develops during epitaxial $\beta$ grain growth [16][17][18] was no longer generated. Instead, a significantly weaker texture was observed (Figure 10).

These observations confirmed the results recently obtained by Kumar et al. [20] who also reported a shift from columnar to near-equiaxed grains by increasing the layer thickness and lowering the energy density. Similarly, Xu et al. [9] obtained equiaxed prior $\beta$ grains in LPBF Ti$6 \mathrm{Al}-4 \mathrm{~V}$ parts built with a relatively high layer thickness of $60 \mu \mathrm{m}$, although they attributed this transition from columnar to equiaxed mesostructure to the use of a higher operating temperature. These results demonstrated the feasibility of breaking down the columnar grains, hence reducing the anisotropy in mechanical properties that can be associated with this directional mesostructure. The genesis of smaller, hemispherical $\beta$ grains could here be achieved by the use of specific process parameters, rather than by tailoring the alloy content (e.g. via the addition of alloying elements such as Mo or $\mathrm{Zr}$ inducing destabilization of the planar solidification front [22]).

Despite the difference in $\beta$ grain morphology, very fine acicular $\alpha^{\prime}$ laths were observed in both hull and bulk, indistinctly (Figures 8.b. and 8.d.). This metastable martensitic microstructure, systematically observed in as-built LPBF Ti-6Al-4V, resulted from the very high cooling rates encountered during the process, which induced a diffusionless $\beta \rightarrow \alpha^{\prime}$ phase transformation. Based on the very similar micrographs and equivalent microhardness results (Figure 11) obtained in both hull and bulk, the increase in layer thickness and associated decrease in energy density applied to build the bulk did not seem to impact the microstructure genesis during cooling from the $\beta$ phase. In both regions, the cooling rate was sufficient to generate martensite. As the $\beta \rightarrow \alpha^{\prime}$ phase transformation occured, the genesis of $\alpha^{\prime}$ variants within each parent $\beta$ grain was dictated by the Burgers orientation relationship, which states that up to 12 crystallographic variants can form within each prior $\beta$ grain [23]. As a result, the anisotropy and texture that were observed at high temperature were considerably reduced in the process of this phase transformation. 


\subsection{Effect of the microstructure on the mechanical properties}

Although hull-bulk tensile specimens mostly contained hemispherical parent $\beta$ grains, their tensile properties (Figure 12 and Table 5) and fracture behavior (Figure 13) remained very similar to those of reference parts with a fully columnar mesostructure. This was the case for all three build directions considered in this study. This points to a very limited influence of the $\beta$ grains morphology on the static mechanical properties, which rather appears to be governed by the microstructure within the prior $\beta$ grains.

The influence of the parent $\beta$ grains morphology might however be more visible in terms of fatigue properties. Fatigue crack propagation is known to occur preferentially along the prior $\beta$ grain boundaries [20]. Consequently, a more columnar morphology might induce anisotropy in fatigue resistance. Little effect is however expected in terms of fatigue crack initiation, as initiation usually occurs at the surface - built with the conventional $30 \mu \mathrm{m}$ LT parameter set and is typically not significantly influenced by the microstructure. The effect of the hull-bulk properties on dynamic properties of Ti-6Al-4V will be the topic of future investigations.

\section{Conclusions}

The productivity increase resulting from the implementation of a hull-bulk strategy was directly related to the part's geometry, and became substantial when this approach was applied to relatively bulky parts. The surface-to-volume ratio could be used as a valid parameter to evaluate the relevance of using a hull-bulk strategy and to compare the efficiency of this approach for various geometries. A productivity increase higher than $25 \%$ is typically achieved for the production of parts with a surface-to-volume ratio lower than $5 \mathrm{~cm}^{-1}$. However, when the surfaceto-volume ratio exceeds $10 \mathrm{~cm}^{-1}$, the use of a hull-bulk strategy is not recommended, as its effect on productivity becomes negligible or detrimental.

Despite the use of different processing parameters in the hull and bulk regions, a similar martensitic microstructure was observed in both locations, resulting in comparable mechanical properties. The gradient in mesostructure that was observed between hull and bulk, namely the presence of columnar prior $\beta$ grains in the hull, as opposed to more hemispherical grains in the bulk, did not appear to influence the microhardness and tensile properties. The present study confirmed the feasibility of breaking down the columnar mesostructure - typically observed in powder-bed additively manufactured Ti-6Al-4V - by applying a lower energy density during the process. The mesostructure and associated prior $\beta$ grain texture could be controlled to some extent at a local scale by a fine tuning of the process parameters, hence opening the way to the development of graded materials.

Overall, this work demonstrated that applying a hull-bulk strategy during LPBF of Ti-6Al-4V could be beneficial for productivity, while maintaining a high quality in terms of surface finish, relative density and tensile properties of the parts.

\section{Acknowledgements}

This research was funded by the Combilaser SBO project. We acknowledge Dr Loïc Malet and Dr Benjamin Hary from the 4MAT department (ULB) for their help in the numerical reconstruction of the parent $\beta$ grains and Gokulakrishna Muralidharan for the EBM-LPBF productivity analysis. 


\section{References}

[1] M. Ma, Z. Wang, M. Gao, X. Zeng, Layer thickness dependence of performance in high-power selective laser melting of $1 \mathrm{Cr} 18 \mathrm{Ni}$ Ti stainless steel, Journal of Materials Processing Technology. 215 (2015) 142-150.

[2] A. Cutolo, B. Neirinck, K. Lietaert, C. de Formanoir, B. Van Hooreweder, Influence of layer thickness and post-process treatments on the fatigue properties of CoCr scaffolds produced by laser powder bed fusion, Additive Manufacturing. 23 (2018) 498-504.

[3] A. du Plessis, Effects of process parameters on porosity in laser powder bed fusion revealed by X-ray tomography, Additive Manufacturing. 30 (2019) 100871.

[4] M. Brandt, The role of lasers in additive manufacturing, in: Laser Additive Manufacturing, Woodhead Publishing, 2016: pp. 1-18.

[5] R. Poprawe, C. Hinke, W. Meiners, J. Schrage, S. Bremen, S. Merkt, SLM Production Systems: Recent Developments in Process Development, Machine Concepts and Component Design, in: Advances in Production Technology, Springer, 2014: pp. 49-65.

[6] H. Schleifenbaum, A. Diatlov, C. Hinke, J. Bültmann, H. Voswinckel, Direct photonic production: towards high speed additive manufacturing of individualized goods, Production Engineering. 5 (2011) 359-371.

[7] J. Metelkova, Y. Kinds, K. Kempen, C. de Formanoir, A. Witvrouw, B. Van Hooreweder, On the influence of laser defocusing in Selective Laser Melting of 316L, Additive Manufacturing. 23 (2018) 161-169.

[8] D. Koutny, D. Palousek, L. Pantelejev, C. Hoeller, R. Pichler, L. Tesicky, J. Kaiser, Influence of Scanning Strategies on Processing of Aluminum Alloy EN AW 2618 Using Selective Laser Melting, Materials. 11 (2018).

[9] W. Xu, E.W. Lui, A. Pateras, M. Qian, M. Brandt, In situ tailoring microstructure in additively manufactured Ti-6Al-4V for superior mechanical performance, Acta Materialia. 125 (2017) 390-400.

[10] W. Xu, M. Brandt, S. Sun, J. Elambasseril, Q. Liu, K. Latham, K. Xia, M. Qian, Additive manufacturing of strong and ductile Ti-6Al-4V by selective laser melting via in situ martensite decomposition, Acta Materialia. 85 (2015) 74-84.

[11] L. Thijs, F. Verhaeghe, T. Craeghs, J. Van Humbeeck, J.P. Kruth, Acta Materialia. 58 (2010) 3303-3312.

[12] S.S. Al-Bermani, M.L. Blackmore, W. Zhang, I. Todd, The Origin of Microstructural Diversity, Texture, and Mechanical Properties in Electron Beam Melted Ti-6Al-4V, Metallurgical and Materials Transactions A. 41 (2010) 3422-3434.

[13] B. Vrancken, L. Thijs, J.P. Kruth, J. Van Humbeeck, Heat treatment of Ti6Al4V produced by Selective Laser Melting: Microstructure and mechanical properties, Journal of Alloys and Compounds. 541 (2012) 177-185.

[14] T. Vilaro, C. Colin, J.D. Bartout, As-Fabricated and Heat-Treated Microstructures of the Ti-6Al-4V Alloy Processed by Selective Laser Melting, Metallurgical and Materials Transactions A. 42 (2011) 31903199.

[15] L. Germain, N. Gey, M. Humbert, Reliability of reconstructed beta-orientation maps in titanium alloys, Ultramicroscopy. 107 (2007) 1129-1135.

[16] M. Simonelli, Y.Y. Tse, C. Tuck, On the Texture Formation of Selective Laser Melted Ti-6Al-4V, Metallurgical and Materials Transactions A. 45 (2014) 2863-2872.

[17] C. de Formanoir, S. Michotte, O. Rigo, L. Germain, S. Godet, Electron beam melted Ti-6Al-4V: Microstructure, texture and mechanical behavior of the as-built and heat-treated material, MSEA. 652 (2016) 105-119.

[18] L. Thijs, B. Vrancken, J.P. Kruth, J. Van Humbeeck, The Influence of Process Parameters and Scanning Strategy on the Texture in Ti6Al4V Parts Produced by Selective Laser Melting, Advanced Materials, Processes and Applications for Additive Manufacturing. 1 (2013) 21-28.

[19] K.N. Amato, Gaytan, S.M., L.E. Murr, E. Martinez, P.W. Shindo, D.H. Hernandez, S. Collins, F. Medina, Microstructures and mechanical behavior of Inconel 718 fabricated by selective laser melting, Acta Materialia. 60 (2012) 2229-2239.

[20] P. Kumar, O. Prakash, U. Ramamurty, Micro- and meso-structures and their influence on mechanical properties of selectively laser melted Ti-6Al-4V, Acta Materialia. 154 (2018) 246-260.

[21] J. Yang, H. Yu, J. Yin, M. Gao, Z. Wang, X. Zeng, Formation and control of martensite in Ti-6Al-4V alloy produced by selective laser melting, Materials \& Design. 108 (2016) 308-318.

[22] B. Vrancken, L. Thijs, J.P. Kruth, J. Van Humbeeck, Microstructure and mechanical properties of a novel $\beta$ titanium metallic composite by selective laser melting, Acta Materialia. 68 (2014) 150-158.

[23] G. Lütjering, J.C. Williams, Titanium, Springer, 2007. 